\title{
The Role of Constitutional and Environmental Factors in Susceptibility to Duodenal Ulcer
}

\author{
M. Mujahid Ali, Ph.D., C. M. Habibullah, M.D., D.M., M. Ishaq, Ph.D.," Mahboobunnisa, M. Sc. \\ Hyderabad, India
}

DOI: http://dx.doi.org/10.5915/21-4-13512

\begin{abstract}
We studied 1250 duodenal ulcer patients during an eight year period to see the role of constitutional and environmental factors in the etiology of duodenal ulcer disease. All the patients studied were endoscopically proven to have duodenal ulcer. In our area, duodenal ulcer was found 15 times more frequently than gastic ulcer. It was more common in males and the highest incidence was recorded between 20 and 40 years of age. The disease was unaffected by the seasons and no significant ethnic variation was observed; however, the disease was associated with belonging to low income groups and unskilled professions. It was more common among rice eaters, those who were irregular in taking meals, and it was common in nonvegetarians. Consumption of alcohol, tea or coffee was not associated with the disease, but the disease was more prevalent among smokers than nonsmokers. Pan chewing habit did not have any bearing on the disease pattern.
\end{abstract}

Key words: Duodenal ulcer, etiology, environmental factors.

Duodenal ulcer (DU) is a common gastrointestinal disorder with high morbidity rate. People living in tropical as well as temperate regions are affected by this disease. Over the past two decades much research has been carried out on various aspects of this clinical condition, including epidemiology, genetics, diagnosis, and medical and surgical treatment.

The role of constitutional and environmental factors in susceptibility to DU has been investigated by some workers. ${ }^{1-4}$ Most of the reports deal with the possible role of one or two factors in susceptibility to ulceration and no single factor can be taken as an absolute determinant of liability to DU. We decided to carry out a comprehensive study investigating constitutional and environmental factors. We thought that an epidemiological investigation of this type might provide more meaningful results, as the role of

From the Department of Gastroenterology

Osmania General Hospital and *Department of Genetics Osmania University, Hyderabad, India

Reprint Requests: Dr. M. Mujahid Ali

Department of Gastroenterology

Osmania General Hospital

Hyderabad, (A.P.) India. multiple factors could be evaluated in the same series of patients.

\section{Materials and methods}

Twelve hundred and fifty DU patients of both sexes, 16 and 75 years of age, were selected from among patients treated in the Gastroenterology Department, Osmania General Hospital, Hyderabad, over an eight year period from July 1980 to June 1988. After a preliminary clinical evaluation, patients with symptoms syggestive of DU underwent endoscopy and the size and location of ulcer, if present, was recorded. Only endoscpically positive DU cases were included in the study. One hundred healthy controls matched by sex and age but without previous history of ulcer disease were also included in this study. Details regarding age, sex, religion, dietary habits, addiction to alcohol, pan chewing, smoking, socio-economic and professional status of each patient and control were recorded. The data obtained were also analyzed for ethnic and seasonal variations in the incidence of the disease.

Results

Incidence

A total of 7674 patients underwent endoscopy. Of 


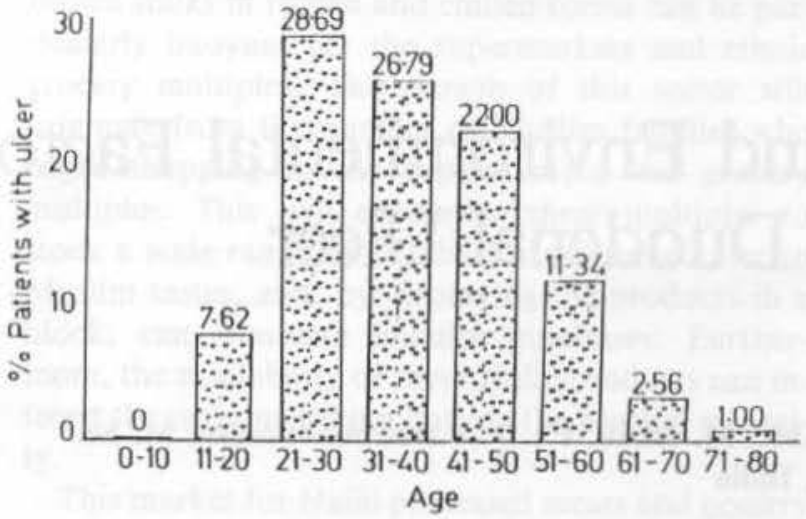

\section{Figure 1}

Total number of patients distributed according to age group.

these, $1432(18.7 \%)$ had DU, $96(1.3 \%)$ had gastric ulcer (GU), $43(0.6 \%)$ had prepyloric channel ulcer and $13(0.2 \%)$ had stomal ulcer. The ratio between DU and GU was 14.9: 1.

\section{Age and sex distribution}

The percentages of cases falling in the different age ranges were as follows: $7.6 \%$ from 16 to 20 years; $28.7 \%$ from 21 to 30 years; $26.8 \%$ from 31 to 40 years; $22.9 \%$ from 41 to 50 years; $11.3 \%$ from 51 to 60 years; $2.6 \%$ from 61 to 70 years; and $1.0 \%$ from 71 to 80 years (Figure 1). Sex distribution analysis revealed a ratio of 8 males to one female (8:1).

\section{Seasonal Variation}

During this eight year period the incidence of the disease during the three seasons was recorded as follows: $21.5 \%$ in monsoon (June to September); $21.2 \%$ in winter (October to January); and $17.6 \%$ in summer (February to May).

\section{Ethnic variations}

Details of the incidence of the disease in three communities, Hindu, Muslim and Christian, of Hyderabad were recorded. The normal percentage of people belonging to these communities is as follows: $63.2 \%$ Hindus; $35.9 \%$ Muslims, and $0.9 \%$ Christians. In the patient group there were $852(68.2 \%)$ Hindus; $394(35.5 \%)$ Muslims and $4(0.3 \%)$ Christians. The incidence of ulcer was not higher in any particular community.

\section{Socio-economic status and occupation}

Patients were grouped according to their monthly income and professional status. The results obtained were as follows: $72.2 \%$ had a monthly income of Rs. $1,000 /$ - or less; $24 \%$ cases between Rs. $1,000 /$-and Rs.2,000/-; and 3.3\% belonged to a higher income group of more than Rs.2,000/- monthly.
Table 1. Incidence of Duodenal Ulcer Disease According to Professional Status.

\begin{tabular}{lrc}
\hline Profession & & $\mathbf{( \% )}$ \\
\hline Officers (including doctors & & \\
$\quad$ and engineers) & 44 & $(3.52)$ \\
Businessmen & 143 & $(11.4)$ \\
Low paid clerks & 201 & $(16.1)$ \\
Farmers and laborers & 603 & z) 48.2$)$ \\
Teaching staff (including & & \\
$\quad$ teachers and lecturers) & 53 & $4.2)$ \\
Students & 71 & $(5.7)$ \\
Pensioners and housewives & 135 & $(10.8)$ \\
\hline
\end{tabular}

The disease was found to be more frequent in patients who worked in unskilled professions. This is evident from the observation that a high percentage $(48.2 \%)$ of cases were farmers and laborers. (Table 1)

\section{Dietary habits}

Details of the dietary habits of the patients recorded were as follows: vegetarian or non-vegetarian; regularity in taking meals; daily consumption of rice, wheat and jowar (sorghum). Similar information was recorded in 100 age and sex matched controls for the purpose of comparison. Of a total 1250 cases, 189 $(15.1 \%)$ were vegetarians and $1061(84.9 \%)$ were non-vegetarians. Among 100 control subjects studied, $30 \%$ were vegetarians and $70 \%$ were nonvegetarians. A significant difference $(p<0.001)$ between dietary habits (vegetarian vs. non-vegetarian) of patients and controls was observed. The percentage of patients who were not regular in taking meals was $74.7 \%$. Information obtained regarding the daily consumption of rice, wheat and sorghum revealed that $50.3 \%$ of patients consumed rice twice daily, and wheat or sorghum once daily; $35.8 \%$ consumed rice three times daily; $6.3 \%$ consumed rice once and sorghum or wheat two times daily; while only $7.5 \%$ consumed only wheat or sorghum daily. In the control population, $40 \%$ people consumed rice twice and wheat or sorghum once daily, $25 \%$ consumed rice three times daily, $12 \%$ consumed rice once and sorghum or wheat twice daily, and $23 \%$ consumed only wheat or sorghum daily. The difference between the daily intake of rice, wheat, and sorghum in patients vs. controls was statistically significant $(\mathrm{P}<0.05)$.

Alcohol

There were ninety patients $(7.2 \%)$ who consumed alcohol daily and 178 patients $(14.2 \%)$ who consumed moderate to mild quantities of alcohol. The remaining $982(78.6 \%)$ patients did not consume any alcohol. Among the controls $37 \%$ were addicted to 
alcohol and $63 \%$ did not consume any alcohol. Ulcers were observed significantly more frequently $\left(\mathrm{x}^{2}=8.05 ; \mathrm{p}<0.05\right)$ in non-imbibing patients as compared with non-imbibing controls.

\section{Smoking}

Analysis of the data obtained regarding smoking habits revealed that $796(63.7 \%)$ cases were smokers (averaging 10-15 cigarette or Beedies per day), and $454(36.3 \%)$ were nonsmokers. Among the 100 healthy controls studied $37 \%$ were smokers and $63 \%$ nonsmokers. There was a significant association between smoking habit and ulcer incidence observed among the patients. $\left(x^{2}=26.9 ; p<0.001\right)$

\section{Tea and coffee}

Tea and coffee consumption (average 3-5 cups per day) in patients as well as controls showed 763 $(61.0 \%)$ patients consumed tea or coffee daily. In the control population, $55 \%$ of people took tea or coffee daily (3-5 cups). There was no significant difference between patients and controls based on tea or coffee consumption.

\section{Pan chewing habit}

Information obtained regarding pan chewing patients as well as controls showed $129(10.3 \%)$ patients chewed pan. Among healthy controls $15 \%$ chewed pan. There was no significant difference associated with the pan chewing habit in patients when compared with controls.

\section{Discussion}

Duodenal ulcer is a general health problem throughout the world. It is believed that at least $10 \%$ of the population may be affected by this disease at some time in their lives. Studies of the etiology and pathogenesis are important in view of the limitations of medical treatment of DU. Relapses have been reported to be common in those patients who are not on maintenance therapy. Cimetidine or Ranitidine are important $\mathrm{H}_{2}$ receptor antagonists, but these drugs have undesirable side effects in DU patient. Surgical therapy also may be associated with complications. Thus, a better understanding of the predisposing factors would be of great help in better management of these cases. A careful analysis of age of onset, sex, psychological factors, smoking habits, alcohol consumption, diet, professional status, etc., of the patients is likely to provide useful information about the etiologocal factors of ulceration.

Duodenal ulcer is usually rare before the age of 15 years, but becomes more frequent as middle age approaches. In a study conducted in Punjab, Chuttani in $1964^{\mathrm{s}}$ reported that the highest incidence of the disease occurs in the fourth decade of life. A similar study was carried out in Trivandrum by Dogra (1940), ${ }^{4}$ and also observed the maximum incidence during the fourth decade of life. In our study the highest incidence was observed between the third and fourth decades of life. These observations corroborate the results reported by Dogra, Chuttani and Tovey..$^{4-6}$

Striking differences have been observed in the incidence of DU in the two sexes. The disease is eight times more common in males than in females, ${ }^{1,4,6,7}$ which is similar to that reported by Chuttani. ${ }^{5}$ Studies carried out in Western countries ${ }^{8}$ have shown the disease to be twice as common in males as in females. It has been suggested that hormonal factors may be responsible for this male-female difference. Another reason for this difference could be the fact that the females in our country are usually nonsmokers. However, there is a need for further study to explain the observed sex difference in DU.

Analysis of the data in our study indicates that the incidence of DU was about 15 times higher than that of GU (15:1) in this part of our country. Raghvan and Antia from Bombay, ${ }^{10}$ reported the DU to GU ratios as $6.4: 1$ and $8.7: 1$ respectively where as Chuttani" $^{11}$ from Delhi reported a 30:1 ratio. This difference may be due to different eating habits and climatic conditions.

Our study has shown there were no significant seasonal variations in the incidence of the disease in our area. The incidence of the disease was not different for the three religious communities, Hindu, Muslim and Christian, of Hyderabad. Although a previous report by Raghvan? from Bombay showed a high incidence of the disease in Hindus, Antia ${ }^{10}$ found no difference based on religious groups.

In the present study, DU patients were grouped according to their monthly income and profession. A predominant number $\mathbf{7 2 . 7 \%}$ ) were in the low income group (monthly income of Rs.1,000/- or less per month); while the high income group (more than Rs. 2,000 /- per month) represented only $3.33 \%$ of patients. The disease was found to be more common in low income group with unskilled or semi-skilled occupations. These observations are in agreement with those reported from the USA and England. ${ }^{12,13}$

A strong association has been reported between the prevalence of DU and the consumption of diets of low residue with less masticatory content. ${ }^{1,8}$ Low incidence has been recorded in Punjab ${ }^{14}$ and Delhi, ${ }^{15}$ where unrefined wheat with high masticatory content is the staple diet. The disease appears to be more frequent among those who predominantly eat rice. In our study rice was the predominant staple food of $86 \%$ of patients while only $7.5 \%$ consumed wheat or sorghum daily. Malhotra ${ }^{1,16}$ suggested that an unrefined wheat with high masticatory content produces a bigger volume of saliva with a higher bicarbonate and mucus content than that resulting from the sloppier rice diet. Thus it is believed that a diet rich in fiber increases mastication and can protect the 
mucosa from ulceration.

The disease also appeared to be more frequent in those who were irregular in taking meals, particularly lunch. Similar results were also recorded from two population surveys from Delhi ${ }^{11}$ and Vellore, ${ }^{17}$ suggesting that long interval between meals is a possible factor for peptic ulcer disease. In our study ulcers were commonly found in persons who prefer nonvegetarian food. A study conducted by Jayaraj et al ${ }^{18}$ showed protective action against ulceration by various vegetarian foods such as black gram, green gram, and horse gram; millets such as sava kutki and soyabean; and vegetables such as ladies finger, cabbage and spinach. Whole cream milk also was found to be more protective than a non-vegetarian food.

Current evidence suggests that mild to moderate alcohol consumption may have little or no effect on liability to ulcer ${ }^{2,3}$ while effects of heavy consumption are unclear. In the present study it was observed that only $24 \%$ of patients consumed alcohol daily, weekly or occasionally, while $78.6 \%$ did not imbibe any alcohol. The disease occured significantly more often in non-imbibing individuals when compared to healthy controls $(\mathrm{p}<0.05$ ). In light of these observations, it may be concluded that consumption of alcohol does not increase liability to ulceration.

It has been suggested that smoking may be one of the predisposing factors for DU. In a review article, Langman $^{8}$ concluded that the association between smoking and ulcer is weak, and the habit can at best play only a minor casual role in ulcer development. Out of a total of 1250 cases included in the present study $796(63.2 \%)$ were smokers. An increased frequency of ulcer has been recorded among smokers compared with nonsmokers. Population surveys from Chandigarh and Delhi ${ }^{11,19}$ also reported an increased number of smokers among DU patients. Dogra ${ }^{4}$ reported $64.7 \%$ of patients with peptic ulcer were smokers of indigenous cigarettes called "Beedies". Freidman et $\mathrm{al}^{3}$ have reported that about $57 \%$ of DU patients were smokers. In view of those observations it may be concluded that smoking may be one of the predisposing factors for DU.

Tea and coffee consumption increases gastric acid secretion and it has been suspected of predisposing to or of aggravating peptic ulcer. ${ }^{3}$ Black tea has been shown to produce an acid output equal to $89 \%$ of that obtained by maximal histamine stimulation in DU patients and controls. The response is reduced to $57 \%$ if milk and sugar are added. In our population all people took tea with milk and sugar, and prefered tea instead of coffee. We could not find any significant association between consumption of tea or coffee and DU. An association of peptic ulcer disease with consumtion of coffee and black tea was reported earlier. ${ }^{20}$

Addiction to pan chewing did not have any effect on the disease pattern.

\section{References}

1. Malhotra SL. Peptic ulcer in India and its etiology. Gut 1964; 5:412-416.

2. Tovey FI. Geographical distribution and possible factors in the etiology of peptic ulcer. Tropical Doctor $1974 ; 4: 17-21$.

3. Freidman GD, Siegglaub AB, Seltrer CC. Cigarettes, alcohol, coffee and peptic ulcer. New Engl J Med 1974; 290:469-473.

4. Dogra JR. Studies on peptic ulcer in South India II. A statistical survey. Ind J Med Res 1940; 28:481-507.

5. Chuttani PN, Agarwal ML, Harijit S, Sehgal AK. Peptic ulcer in Punjab. A review of 145 patients. J Ind Med Assoc 1964; 42:422-428.

6. Tovey FI. Peptic ulcer in India and Bangladesh. Gut 1979; 20:329-347.

7. Choudhrie AW. Duodenal ulcer: Possible etiology. An observation. J of Christ Med Assoc India $1974 ; 49: 160-161$.

8. Langman MJS. The Epidemiology of Chronic Digestive Disease. London: Arnold, 1979.

9. Raghvan P. Epidemiology and clinical behavior of peptic ulcer in Bombay, India. Gastroenterology 1962; 42:130-143.

10. Antia EP, Bhatnagar SB, Vyas MC. Incidence of peptic ulcer and gastric cancer in Bombay. Proceedings of the World Congress of Gastroenterology 1959; 1:379-385. (Baltimore: Williams and Wilkins).

11. Chuttani CS, Wing, Wig KL, Chablani TD, Vasudeva YL, Gadekar NG, Chuttani HK. Epidemiology of peptic ulcer I. A prevalance of peptic ulcer in an urban community in Delhi. Ind J Med Res 1967; 55:1121-128.

12. Guralnic L. Mortality by occupational level and cause of death among men 20 to 60 years of age. United States Vital Statistical Special Report $1963 ; 53: 439$.

13. Litton A, Murdoch WR. Peptic ulcer in South West Scotland. Gut 1963; 4:360-369.

14. Jayaraj AP, Tovey FI, Clark CG. The possibility of dietary productive factors in duodenal ulcer II. An investigation into the effect of prefeeding with different diet and of instillation of food stuff into the stomach on the incidence of ulcers in pylorus-ligated rates. Post Grad Med J 1976; 52:640-644.

15. Tovey FI, Jayaraj AP, Clark CG. The possibility of dietary protective factors in duodenal ulcer. Post Grad Med J 1975; 51:366-372.

16. Malhotra SL, Saigal ON, Mody GD. Role of saliva in the etiology of peptic ulcer. Brit Med J $1965 ; 1: 1220-1222$.

17. Benjamin V, Narielwala FM. Population survey of peptic ulcer in rural communities. Proceedings of Second Asian Congress of Gastroenterology 1964; Banglore, P. 44. 
18. Jayaraj AP, Tovey FI, Clark CG. Possible dietary protective factors in relation to the distribution of duodenal ulcer in India and Bangladesh. Gut 1980; 21:1068-1076.

19. Sehgal AK, Chuttani PN, Gupta BB, Malik K, Gupta HD. Epidemiology of peptic ulcer in an urban community in Chandigarh. Ind J. Med
Res 1971; 59:1612-1620.

20. Dubey P, Nundy S. The effect of tea on gastric acid secretion (All India Institute of Medicine Science, New Delhi) presented at the XIX Annual Conference of the Indian Society of Gastroenterology, at Simla, 1978 (abstract of papers, p. 66-67). 